\title{
Uma inovação aparente
}

\section{An apparent innovation}

\author{
Iara Bemquerer Costa ${ }^{1}$
}

\begin{abstract}
RESUMO
Discute-se no artigo o uso da internet em atividades de produção escolar de textos, a partir de um exemplo de atividade desenvolvida por alunos de oitava série do ensino fundamental. No caso em foco, os alunos foram orientados a produzir textos argumentativos a partir de instruções disponibilizadas no Portal Educacional de uma instituição particular de ensino, que tem escolas conveniadas em vários pontos do Brasil. Os textos foram produzidos no computador e enviados para um avaliador na sede da instituição. $\mathrm{O}$ artigo discute inicialmente as orientações disponibilizadas on line para os alunos e professores. Em seguida, analisa um conjunto de 120 textos produzidos em duas escolas, uma situada em São Paulo - SP, outra em Fortaleza - CE. As orientações do Portal Educacional mostram a permanência de uma concepção tradicional de produção da dissertação escolar. Os textos produzidos on line pelos alunos das duas escolas escolhidas confirmam a mesma concepção tradicional. $\mathrm{O}$ caso estudado revela um descompasso entre a inovação tecnológica na escola e seu uso nas aulas de língua portuguesa. O computador e a internet dão uma aparência de modernidade a atividades tradicionais. Para finalizar, são indicadas alternativas para inovar a produção de textos e obter resultados mais interessantes com uso das tecnologias digitais.
\end{abstract}

Palavras-chave: Textos argumentativos; Redação on line.

\begin{abstract}
The present article discusses the use of the internet in activities related to text production in schools, focusing an activity developed by 8th grade students of the so-called 'fundamental school' in Brazil. In this particular case, the students were asked to produce argumentative texts according to instructions available in the Educational Site of a private teaching institu-
\end{abstract}

1 Doutora em Linguística (Unicamp), docente da UFPR. E-mail: iarabemq@ufpr.br. 
tion, which maintains covenantal schools in many cities in Brazil. The texts were produced in computers and sent to an evaluator in the institution's head-office. Initially, the present article discusses the guidelines offered on-line for students and teachers. Then, it analyzes a set of 120 texts produced in two schools, one in São Paulo-SP and the other in Fortaleza-CE. The guidelines contained in that Educational Site show the persistence of a traditional approach to the production of school articles. The texts produced on-line by the students of both chosen schools confirm this traditional approach. The studied case reveals an unsteadiness between the technological innovation detected in the school and its use in Portuguese language classes. The computer and the internet give a seeming modernity to traditional activities. Finally, alternatives to innovate text production and to obtain more interesting results with the use of digital technologies are pointed out.

Keywords: Argumentative texts; On line text production.

\section{Introdução}

Os últimos anos foram marcados pela expansão do uso da informática, que se tornou ferramenta fundamental para um número cada vez maior de atividades. Como não podia deixar de acontecer, observa-se a presença crescente do computador e da Internet nas escolas, como recursos pedagógicos para o trabalho em diversas disciplinas. A informática na escola veio para ficar; se no momento ainda é incipiente seu uso em atividades de leitura e produção de textos, é porque ainda vivemos uma fase de transição: enquanto na maioria das escolas ainda se escreve quase exclusivamente no papel, em outros contextos toda a produção escrita se faz na tela do computador.

Seria interessante que a inovação tecnológica associada à expansão do uso da informática fosse acoplada à inovação metodológica nas atividades de produção de textos na escola, que se observa, em especial, a partir da publicação em 1997/1998 dos Parâmetros Curriculares Nacionais. Essa inovação caracterizase por atribuir aos gêneros textuais um papel nuclear nas atividades de leitura e escrita. A didatização de um conjunto de gêneros textuais, selecionados do amplo universo de gêneros em circulação social dentro e fora da escola, tornase o centro da aprendizagem da escrita, em substituição ao ensino tradicional da redação escolar.

Nem sempre a inovação tecnológica caminha junto com a mudança nos fundamentos da produção de textos na escola. A valorização social da tecnologia 
pode incentivar as escolas (particulares especialmente) a ampliarem o uso de computadores e da Internet em suas atividades, sem que se renove paralelamente a concepção do ensino da leitura e escrita.

Vamos discutir neste artigo um caso típico de uso da Internet para a produção de texto (o que é muito interessante) acoplada a uma concepção tradicional de redação escolar (que esperaríamos ver renovada). Não queremos, de forma alguma, nos colocar na contramão do uso da informática para a leitura e produção de textos na escola. Pelo contrário, esse uso pode ter resultados muito interessantes se não ficar limitado a uma substituição do suporte físico pelo virtual.

Tomaremos como exemplo para orientar essa discussão uma atividade de produção de texto argumentativo, apresentada no Portal Educacional de uma instituição particular de ensino, que tem escolas conveniadas de nível fundamental e médio em vários pontos do Brasil. As orientações para a produção de texto foram disponibilizadas no site da instituição, com orientações para a produção de textos, em atividade monitorada pelo professor de língua portuguesa. Os textos produzidos on-line foram enviados para a equipe de avaliadores, que atuava na sede da instituição e centralizava a leitura e correção/avaliação dos textos produzidos em vários lugares.

Procuraremos inicialmente comentar as várias etapas da atividade de leitura e produção de texto proposta, a partir das orientações aos alunos e professores. A seguir vamos discutir os resultados da atividade realizada, a partir da análise de 120 textos produzidos on-line por alunos de duas escolas conveniadas, uma da Região Sudeste (São Paulo-SP), outra do Nordeste (Fortaleza-CE)². A apresentação em detalhes da atividade proposta está em De Cristo (2005).

\section{A proposta}

A atividade de leitura e escrita direcionada aos alunos da $8^{a}$ série do ensino fundamental definia o tipo de texto esperado - argumentativo - e apresentava também o tema - É possível envelhecer com dignidade? A preparação para a produção de texto tinha início com o vídeo Olhos pasmados, de Jurandir Muller e Kiko Goifmam, um documentário experimental que retrata algumas situações críticas que o idoso enfrenta: a dor, a miséria, o abandono, os problemas de saúde. Além do vídeo, a proposta reproduzia o Artigo I da Declaração Universal dos

2 Os dados analisados foram coletados por Cláudio Tuma de Cristo, que os utilizou em sua dissertação de mestrado Progressão referencial em redações on-line, defendida no Curso de Pós-Graduação em Letras da Universidade Federal do Paraná em 2005. 
Direitos Humanos: "Todos os seres humanos nascem livres e iguais em dignidade e em direitos. Dotados de razão e de consciência, devem agir uns para os outros em espírito de fraternidade.”

Após assistir ao vídeo e ler o artigo da Declaração universal dos direitos humanos, o aluno era convidado a produzir seu texto a partir da seguinte orientação:

Com base no vídeo que você acabou de assistir e no Artigo I da Declaração Universal dos Direitos Humanos, elabore um texto para defender seu ponto de vista em relação às dificuldades enfrentadas pela maioria dos idosos, abordando os problemas do cotidiano (o abandono pela família, amigos e o desprezo da sociedade) ou os problemas sociais (falta de condições mínimas de sobrevivência, como moradia, alimentação e saúde).

Nossa primeira observação a propósito desse primeiro conjunto de orientações diz respeito à escolha do tema. Os problemas relativos ao envelhecimento são uma realidade muito distante para a maioria dos jovens matriculados na $8^{\mathrm{a}}$ série das escolas particulares, que em geral estão na faixa dos 13 aos 15 anos. Dificilmente esses alunos assumiriam efetivamente a posição de sujeitos para defender um ponto de vista sobre um tema que não os afetava diretamente: os problemas vivenciados pelos idosos das camadas mais pobres, focalizados no documentário. Assim, o tema proposto foi um fator de distanciamento para os autores adolescentes e pode tê-los feito encarar a produção de textos como uma tarefa escolar a ser cumprida.

Ainda sobre a escolha do tema, observe-se que os alunos foram colocados diante de uma pergunta (É possível envelhecer com dignidade?), que comporta essencialmente duas respostas: sim ou não. Como a questão foi proposta no interior da instituição escolar, os pesos da resposta afirmativa ou negativa eram diferentes: responder "não" significa aceitar passivamente a degradação da velhice mostrada pelo documentário, enquanto o "sim" está associado ao engajamento na luta por uma melhoria das condições de vida dos idosos no Brasil. Ou seja, no ambiente escolar a pergunta só comportava efetivamente a afirmação, a menos que os alunos usassem estratégias de modalizar a resposta negativa, como alguns fizeram: "Ainda não é possível envelhecer com dignidade para os idosos que não possuem recursos...", ou "Hoje a possibilidade de envelhecer com dignidade tem se tornado cada vez mais difícil”. Mais que isso, a pergunta apresentada como tema para a produção de texto tem como resposta típica a enumeração daquilo que as pessoas devem fazer para mudar 
as condições de vida dos idosos. Cabe lembrar aqui as observações de Pécora sobre a argumentação centrada na noção de dever:

\begin{abstract}
A argumentação do dever se esgota nela mesma, isto é, na referência a um padrão “a priori”, uma razão oculta e acima do texto, que condena ou aprova esta ou aquela conclusão. [...] O efeito básico desse tipo de argumento é, paradoxalmente, a suspensão da criação de argumentos pelo texto. Em termos mais gerais, poder-se-ia dizer que o seu efeito é o de descaracterizar $\mathrm{o}$ ato de linguagem. Ao receber a tarefa de criar os próprios argumentos, de compor um texto capaz de, pela própria especificidade, agir de modo a convencer o seu interlocutor, o aluno tende a interpretá-la de forma a fazer inveja a um escoteiro. Praticamente, o que ele faz é reduzir o seu texto ao enunciado de uma ordem - na qual, com certeza, ele não tem lugar como sujeito. (PÉCORA, 1983, p. 78-79)
\end{abstract}

A atividade escolar de produção de redações on-line no Portal Educacional era apresentada de forma a provocar também uma diluição na imagem do interlocutor. O texto, uma vez redigido na tela do computador, deveria ser enviado para um professor com o qual os alunos não tinham contato, que faria sua correção/ avaliação e o devolveria ao aluno. A proposta apresentada não definia o grupo de leitores para quem os alunos deveriam escrever, ou seja, não apresentava um direcionamento que contribuísse para a construção de uma imagem do interlocutor com quem eles pudessem interagir. Assim, os alunos produziram seus textos para um interlocutor real, mas desconhecido, cuja imagem foi construída por cada um a partir da representação do professor de português resultante de sua experiência escolar.

O conjunto de orientações aos alunos apresentava ainda dois blocos de orientações suplementares: um conjunto de instruções voltadas para a organização do texto; a indicação de endereços na Internet com informações suplementares sobre o tema.

Vejamos essas orientações:

\title{
Não se esqueça que seu texto deve:
}

a) ser argumentativo, ou seja, defender seu ponto de vista (constituir uma tese);

b) fazer referência, obrigatoriamente, ao menos a um trecho do vídeo;

c) referir-se apenas a um dos temas propostos;

d) apresentar soluções para resolver os problemas apontados no documentário 
Com o intuito de auxiliá-lo na elaboração de seu texto, sugerimos que você procure mais informações para consolidar suas argumentações. Para isso, veja os links abaixo. Você pode visualizá-los antes de iniciar sua redação.

Os links mencionados davam acesso a um conjunto de publicações divulgadas em diferentes sites e têm em comum a apresentação de informações ou o debate sobre os direitos e as condições de vida dos idosos.

As orientações (a) a (d) apresentam aos alunos o que se espera deles na produção de texto: especificam o tipo de texto (argumentativo); apontam a obrigatoriedade do uso das informações contidas no vídeo; mostram que devem optar por uma das abordagens, problemas do cotidiano ou problemas sociais; solicitam propostas de soluções para os problemas apontados no documentário.

A indicação dos links e a previsão de um período para que os alunos naveguem por eles com orientação dos professores têm uma função pedagógica reconhecível e relevante: o uso da Internet para a busca de informações sobre determinados temas. Essa atividade traz para as aulas de Língua Portuguesa o princípio básico de leitura do hipertexto. Ainda que o material de apoio não esteja organizado como um hipertexto, o uso de links para navegação por textos com temas relacionados representa uma oportunidade de orientação aos alunos menos familiarizados com as novas formas de leitura associadas aos gêneros digitais.

Antes da expansão da Internet, os leitores já encontravam uma forma embrionária dos links nas notas de rodapé, elaboradas pelo autor. Nos textos elaborados para circular no meio digital, ampliam-se as possibilidades de associação entre os temas abordados no texto e questões/pontos de vista relacionados. Ao inserir no texto um conjunto de links, o autor aponta os caminhos para que o leitor faça as associações que ele considera relevante em textos que têm a intertextualidade como propriedade constitutiva. Conforme Cavalcante:

A visualização da arquitetura do texto virtual leva à compreensão do hipertexto como um mapeamento de associações possíveis entre textos. Isto é, a tessitura hipertextual funcionaria como uma representação das redes de sentido que estabelecemos na leitura de um texto qualquer. Os links seriam as representações dessas redes que o autor propositalmente apresenta ao leitor, como estratégia de marcar seu próprio percurso enquanto autor, seu estilo, sua história, seu lugar de autoria, e delineando que caminhos o leitor pode perseguir nesta(s) sua(s) leitura(s). (CAVALCANTE, 2005, p. 167) 
Contudo, nas orientações apresentadas a alunos e professores, a possibilidade de desenvolvimento da leitura do texto virtual não é enfatizada. A indicação dos links não é motivada pela preocupação com a formação de leitores em suporte virtual, mas por uma concepção tradicional do que seja a tarefa de produzir textos argumentativos na escola. Procura-se fornecer aos alunos o maior volume possível de informações, a partir do pressuposto de que o acesso a informações é condição necessária e suficiente para a produção da dissertação escolar. A capacidade argumentativa não é relacionada à interlocução entre sujeitos, e sim à organização de informações.

Os alunos tiveram ainda sua atividade de produção de texto direcionada pelo questionário abaixo, que apresenta mais uma faceta da concepção tradicional da produção de textos argumentativos na escola. Esse último conjunto de orientações mostra que escrever um texto argumentativo é, no contexto escolar, uma atividade formal, que pode ser direcionada passo a passo por um roteiro preestabelecido, elaborado sem a participação dos alunos/autores.

\section{Antes de redigir}

1.Reflita sobre as seguintes questões:

a) Quais são os problemas e/ou dificuldades que o documentário apresenta sobre os idosos?

b) Por que eles sofrem com a realidade apresentada?

c) Quem são os responsáveis pelas situações retratadas?

d) O que é possível fazer para reverter esse quadro?

2 . Responda a estas perguntas, que poderão ajudá-lo a definir um ponto de vista para você elaborar seu texto.

a) Para você, qual é o principal problema que os idosos enfrentam?

( ) o desprezo social

( ) o desrespeito aos seus direitos

b) O que impede o idoso de ter uma vida digna?

( ) a vida solitária e a monotonia

( ) a burocracia e a má distribuição de renda (falta de organização governamental)

c) O que os idosos buscam como apoio para superar o abandono?

( ) a espiritualidade

( ) a assistência social

d) Com base no que você assistiu no vídeo, o que você acha que deixaria os idosos mais satisfeitos?

( ) companhia

( ) ter seus direitos respeitados

e) Quem é o maior responsável pelo pessimismo dos idosos? 

( ) a família
( ) o governo
f) Por que a maioria dos idosos não luta pelos seus direitos?
( ) por falta de iniciativa
( ) por falta de informação sobre os seus direitos

O questionário apresenta aos alunos um esquema prévio para a organização do texto. O item (1) propõe um plano global do texto, que pode servir para definir o tema de cada parágrafo. $\mathrm{O}$ item (2) apresenta dois roteiros alternativos: se o aluno optar pela primeira abordagem sugerida na orientação inicial (os problemas do cotidiano), espera-se que ele escolha também a resposta apresentada como primeira alternativa para as questões (a) a (f). Caso selecione a segunda abordagem (os problemas sociais), supõe-se que ele escolheria a segunda alternativa.

A orientação para produção do texto, feita a partir de questões fechadas, é mais um fator para suspender a manifestação do aluno enquanto sujeito na produção do texto, para reduzir essa atividade a um exercício formal, em que seu papel é juntar informações dadas e preencher lacunas com elementos fornecidos pelos textos lidos durante a preparação para a escrita.

Além das instruções dirigidas aos alunos, o Portal Educacional apresentava também um conjunto de orientações aos professores. Estas destacavam aspectos operacionais da atividade de produção de texto on line: nível dos alunos (preferencialmente $8^{\mathrm{a}}$ série do Fundamental), sequência de atividades, aulas previstas. As orientações aos professores enfatizavam repetidamente a importância de se ampliar as informações doa alunos sobre o tema para levá-los a desenvolver sua argumentação.

\section{Os textos produzidos on-line}

Analisamos 120 textos produzidos on-line a partir das orientações divulgadas no Portal Educacional. Uma observação inicial é que, como previmos a partir das instruções apresentadas no site, raros foram os casos em que os alunos constituíram um interlocutor para seu texto. Ou seja, eles escreveram para mostrar o domínio do tema proposto e das normas da escrita, elementos supostamente valorizados pelo leitor dos textos, o distante professor de português. Os textos, quase sempre impessoais, raramente apresentam indícios de 
constituição dos interlocutores: os alunos não se constituem como sujeitos do seu dizer nem incorporam aos textos marcas de um diálogo com o leitor.

As orientações fornecidas aos alunos no Portal Educacional contêm instruções explícitas para a elaboração de um texto argumentativo. Apesar desse direcionamento explícito, foram raros os alunos que assumiram uma posição diante da questão e que sustentaram seu ponto de vista com argumentos. Os textos produzidos on-line só se diferenciam da dissertação escolar tradicional pelo suporte utilizado.

Examinamos esses textos a partir das sequências que os constituem, assumindo, como Adam (2001), que os textos são constituídos de sequências que podem ser de tipos variados. As produções escolares, por sua extensão e organização, são em geral formadas por uma sequência apenas.

Entre os textos selecionados, são raros os constituídos por uma sequência argumentativa, apesar da orientação divulgada no site. Se tomarmos como referência o conjunto de sequências prototípicas proposto por Adam, o protótipo do qual mais se aproximam é da sequência explicativa, que se caracteriza pela seguinte organização:

\section{Sequência explicativa prototípica:}

0

1. Por que $\mathrm{X}$ ?

(ou Como?)

2. Porque...

3.
Macroproposição explicativa 0:

Macroproposição explicativa 1:

Macroproposição explicativa 2:

Macroproposição explicativa 3:
Esquematização inicial

Problema (questão)

Explicação (resposta)

Conclusão - avaliação

(ADAM, 2001, p. 132)

Conforme Adam expõe nesse esquema, as sequências explicativas apresentam três partes (macroproposições), antecedidas opcionalmente por uma apresentação, ou esquematização inicial. Essas sequências caracterizam-se pela apresentação de um problema, feita tipicamente com o uso dos operadores “por quê?” ou “como?”. A pergunta é seguida de uma resposta, ou explicação, introduzida no texto geralmente com o uso do operador "porque". A sequência é encerrada com uma conclusão ou avaliação.

As redações produzidas on-line a partir das instruções do Portal Educacional apresentam, em sua maioria, um esquema de organização que se aproxima do protótipo de sequência explicativa formulado por Adam. Apesar desta aproximação, observam-se algumas diferenças importantes.

Em geral os textos não apresentam a formulação de um problema (por que x? ou como x?) seguido de uma proposta de solução (porque ...). A organização 
predominante dos textos inclui uma primeira parte em que o tema - "condições de vida dos idosos no Brasil” - é introduzido, seguido de uma segunda parte, em que são apresentadas informações adicionais que mostram como os idosos não têm condições de vida dignas, e finalizado por um apelo ao dever, pela afirmação de que alguém deve mudar seu comportamento em relação aos idosos.

Ou seja, os textos não estão centrados em relações de causalidade, nos porquês característicos das sequências explicativas, mas na exposição de uma determinada situação, no como. A aproximação desses textos com o protótipo da explicação se dá exatamente pela possibilidade de explicações centradas na apresentação de como uma determinada situação se apresenta. $\mathrm{O}$ tipo que melhor caracteriza os textos escolares é o expositivo, que Adam (2001) não inclui entre as sequências prototípicas, por considerar que as sequências expositivas apresentam características semelhantes às descritivas.

O conceito de texto expositivo proposto por Milian nos permite caracterizar de forma mais adequada a dissertação escolar:

A denominação "textos expositivos" inclui tanto os textos informativos como os textos explicativos. A diferença entre textos informativos e explicativos é difícil de se estabelecer. Seguindo J.F. Halté (1989), consideramos que os textos informativos privilegiam o conteúdo sobre a situação de comunicação e os textos explicativos, ao contrário, priorizam a situação comunicativa, na qual um emissor, que possui o saber, o torna acessível a um receptor, que não o possui. (MILIAN, 2003, p. 161)

Milian afirma também que, no caso de temas da ordem do saber consolidado, a posição enunciativa do autor tende à neutralidade e à objetividade:

O discurso se organiza em função da referência ao tema: não há marcas diretas da enunciação; não há avaliações subjetivas; a coerência e a progressão temática são marcadas a partir da recuperação anafórica e do uso da passiva; o uso do presente facilita a atualização do objeto do discurso. (MILIAN, 2003, p. 174)

A maioria dos textos produzidos on-line apresenta as características da exposição (do texto informativo, segundo caracterização da autora), combinada, muitas vezes, com um tipo peculiar de conclusão, o apelo ao dever. Ao observar- 
mos o conjunto dos textos escolares, identificamos duas formas de organização características: as sequências expositivas que se limitam à apresentação de informações e as que incluem também o apelo ao dever.

Há ainda um volume considerável de textos que apresentam outras formas de composição. No levantamento feito, deixamos esses textos em um único bloco, para evitar a dispersão que poderia resultar da multiplicação de sequências observadas. O resultado do exame da organização dos textos produzidos pelos alunos paulistas e cearenses está sintetizado na Tabela 1.

Tabela 1 - Composição dos textos

\begin{tabular}{|l|c|c|}
\hline & $\begin{array}{c}\text { Número de } \\
\text { textos }\end{array}$ & $\%$ \\
\hline Sequência expositiva centrada na apresentação de informações & 13 & 10,8 \\
\hline Sequência expositiva (apresentação de informações) + apelo ao dever & 68 & 56,7 \\
\hline Outras formas de composição & 39 & 32,5 \\
\hline TOTAL & 120 & 100 \\
\hline
\end{tabular}

A primeira forma característica de construção dos textos, encontrada em $10,8 \%$ da amostra, pode ser exemplificada pelo Texto 1. Em textos desse tipo, os alunos dão ênfase à exposição do problema. Seu posicionamento frente à realidade apresentada se dá de forma difusa, como se vê no uso do modalizador “infelizmente" e da expressão "não significa nada", no segundo parágrafo.

\section{Texto $1^{3}$}

OIBGE afirma que onúmero de idosos no Brasilé de aproximadamente 15 milhões e em 20 anos poderá ultrapassar 30 milhões, representando $13 \%$ da população.

Infelizmente mesmo com o grande número de idosos e já estarmos no século vinte e um, não significa nada, pois a discriminação ainda é muito grande. Jovens e adultos não os ajudam, não os dão atenção e o principal não os respeitam, porque ainda não passaram por essa fase $e$ não sabem as dificuldades que eles tem.

Grandes empresas e a prefeitura disponibilizaram centros de convivência para o lazer e a saúde da população, pois perceberam que o investimento neles seria bom já que eles serão os jovens de hoje

3 Os textos tomados como exemplos neste estudo foram reproduzidos na versão enviada pelos alunos para o avaliador do Portal Educacional. 
amanhã.

A Tabela 1 deixa claro que a maioria dos alunos (56,7\%) recorreu a um mesmo modelo de estruturação dos textos. A tradição escolar de produção do texto dissertativo e parte das instruções apresentadas no Portal Educacional levaram-nos a ignorar a orientação de que elaborassem textos argumentativos e a escrever a partir de um modelo que lhes é altamente familiar. O vídeo e a leitura dos textos sugeridos nos sites indicados pelos links forneceram os elementos para a organização das informações e a orientação para apresentarem soluções para os problemas apontados no documentário fez com que optassem pelo apelo ao dever, em vez de construir uma argumentação consistente. Essa tendência marcante de argumentar em nome do dever não é característica apenas deste pequeno corpus de redações on-line examinadas aqui, mas já foi apontada por Pécora (1983, p. 78) como predominante também em textos de vestibulandos e universitários.

O Texto 2 ilustra esse modelo.

\section{Texto 2 \\ A velhice com dignidade}

Atualmente, um dos assuntos mais discutidos socialmente éo grande problema dos idosos. Maus tratos, injustiças, solidão, tudo isso vem como uma enxurrada de problemas atrapalhar o envelhecer das pessoas.

Muitos têm o triste destino de ser abandonado pelas próprias famílias, às quais dedicaram toda sua vida. Passam a viver em asilos e casas de apoio, às vezes sem nenhuma condição de manter suas necessidades. Além disso, existe a baixa aposentadoria e os direitos dos idosos que nem sempre são cobrados. Por exemplo, muitos não têm acesso a atendimento médico e chegam a morrer nas filas dos hospitais.

O problema foi tratado na Campanha da Fraternidade do ano passado. O povo se uniu, reivindicou melhores condições de vida, e maior respeito com os idosos. A campanha serviu para conscientizar as pessoas sobre o problema grave que isso está se tornando. Nosso país mantém uma expectativa de vida baixa, o que deve ser mudado.

Todos nós devemos e podemos colaborar com essa situação, pois se a sociedade se unir em um objetivo comum e reivindicar os direitos dos idosos ao governo alguma coisa pode ser melhorada. Uma grande conscientização pode mudar essa história. Os pequenos atos são de igual importância, pois juntos fazem a diferença. Com total união e fraternidade podemos mudar o futuro do Brasil. 
Finalmente, é importante ressaltar que nem todos os textos examinados podem ser reduzidos à mesmice de uma apresentação de informações finalizada ou não pelo apelo ao dever. Cerca de um terço da amostra foge, de uma maneira ou outra, a esse padrão. Há, por exemplo, textos em que os alunos colocam-se como sujeitos e assumem uma posição diante da questão que lhes foi apresentada. Há também alguns casos raros de indícios de que o autor tem um interlocutor em mente.

O Texto 3 combina essas duas características: a) seu autor se dirige a um outro jovem da mesma camada social; b) o aluno compromete-se com uma resposta negativa e modalizada para a questão proposta: “Ainda não é possível envelhecer com dignidade para os idosos que não possuem recursos...”.

\section{Texto 3}

Ao adentrar a bela casa dos seus avós, que lhe darão comida, doces, presentes você nunca parou pra pensar naquele outro idoso que cruzava a rua, carregando uma carroça cheia de material reciclável e restos de comida que serão usados no jantar dele. Você nunca parou para pensar em outros idosos, que apesar de terem uma situação social um pouco melhor, ganhando um salário mínimo, e já com a idade avançada tem de trabalhar para sustentar a si e outros parentes desempregados, sem falar nos remédios caríssimos que estes têm de adquirir todo santo mês para não morrer e deixar na mão seu familiares.

No vídeo experimental "Olhos Pasmados" baseado numa das poesias de Rimbaud, mostra a dura realidade de idosos que sofreram e ainda sofrem na vida, olhando apenas para o fim da vida. O abandono, a solidão, as dificuldades financeiras e principalmente a necessidade de se manter vivo constituem o cotidiano destes velhos. A parte mais chocante do vídeo seria a fala de um senhor, relatando o fato de uma espécie de fiscais das prefeituras roubando suas coisas e as dividindo entre si.

Estes cidadãos desprezados pela maioria são sempre lembrados nos dircursos pré-eleitorais ,onde os políticos prometem mudanças, e mais quatro anos se passam e nada da situação mudar. Porém, este problema tem solução, bastava os governantes se colocar a disposição para trabalhar, criar indústrias estatais onde se possa empregar estes marginalizados, espécies de clubes onde estes possam se divertir e distrair a cabeça, a distribuição de alimentos e etc.

Assim, o problema tem solução, basta os governantes quererem e a sociedade ajudar, pois "a união faz a força". Ainda não é possivel envelhecer com dignidade para os idosos que não possuem recursos, porém com o empenho do governo e da sociedade quem sabe no futura o idoso poderá desfrutar da sua velice de forma digna. 


\section{Direções para inovar a produção de textos na escola}

Schneuwly e Dolz (2004) criticam o ensino tradicional da redação na escola, que mantém uma progressão centrada no grau de complexidade da realidade representada por cada tipo de texto, herança da tradição centenária da retórica. Sua crítica à forma tradicional como a escola trata os gêneros textuais ajuda a esclarecer em que sentido consideramos a atividade de produção de texto descrita acima como tradicional, apesar da roupagem moderna que o suporte digital lhe confere. Segundo eles,

Na sua missão de ensinar os alunos a escrever, a ler e a falar, a escola, forçosamente, sempre trabalhou com os gêneros, pois toda forma de comunicação - portanto, também aquela centrada na aprendizagem cristaliza-se em formas de linguagem específicas. A particularidade da situação escolar reside no seguinte fato que torna a realidade bastante complexa: há um desdobramento que se opera em que o gênero não é mais instrumento de comunicação somente, mas é, ao mesmo tempo, objeto de ensino-aprendizagem. [...] No desdobramento mencionado, é produzida uma inversão em que a comunicação desaparece quase totalmente em prol da objetivação, e o gênero torna-se uma pura forma lingüística, cujo domínio é o objetivo. Em razão dessa inversão, o gênero, instrumento de comunicação, transforma-se em forma de expressão do pensamento, da experiência ou da percepção. $\mathrm{O}$ fato de o gênero continuar a ser uma forma particular de comunicação entre alunos e professores não é, absolutamente, tematizado; os gêneros tratados são, então, considerados desprovidos de qualquer relação com uma situação de comunicação autêntica. Nessa tradição, os gêneros escolares são os pontos de referência centrais para a construção, por meio dos planos de estudo e dos manuais, da progressão escolar, particularmente no âmbito da redação/composição. Seqüências relativamente estereotipadas balizam o avanço através das séries escolares, sendo a mais conhecida e canônica, que pode, entretanto, sofrer variações importantes, a "descrição - narração - dissertação”, gêneros aos quais vem se juntar, em certas épocas históricas, a resenha, o resumo e o diálogo. (SCHNEUWLY; DOLZ, 2004, p. 75-77)

Esses autores assumem que as práticas de linguagem são aquisições acumuladas pelos grupos sociais no curso da história e que se cristalizam na forma de gêneros textuais. Assim, é na circulação social dos gêneros que a escola deve buscar as bases para a construção do seu projeto de ensino da língua. Ou seja, 
cabe à escola selecionar, a partir do extenso repertório de gêneros em circulação na sociedade, aqueles que serão objeto de ensino. É tarefa do sistema escolar definir também as dimensões ensináveis dos gêneros escolhidos e organizar sequências didáticas que direcionem professores e alunos em atividades que resultem na apropriação dos gêneros selecionados.

Orientações semelhantes estão presentes nos Parâmetros Curriculares Nacionais de Língua Portuguesa, que propõem a organização das atividades de leitura e produção de textos na escola a partir de alguns gêneros textuais que circulam fora e dentro da instituição escolar (Brasil 1998, p. 57). Para a produção de textos de $5^{\mathrm{a}}$ a $8^{\mathrm{a}}$ séries do ensino fundamental são sugeridos três conjuntos de gêneros: literários (crônica, conto, poema), de imprensa (notícia, artigo, carta do leitor, entrevista), de divulgação científica (relatório de experiências, esquema e resumo de artigos ou verbetes de enciclopédia). Os PCNs enfatizam também a importância de focalizar, na produção escolar de textos escritos, suas condições de produção: finalidade, especificidade do gênero, lugares preferenciais de circulação e interlocutor eleito (SCHNEUWLY; DOLZ, 2004, p. 58).

Schneuwly e Dolz propõem que o ensino de língua seja organizado a partir de um agrupamento dos gêneros orais e escritos que:

a) correspondam às grandes finalidades sociais legadas ao ensino, respondendo às necessidades de linguagem em expressão escrita e oral, em domínios essenciais da comunicação em nossa sociedade (inclusive a escola);

b) retomem, de modo flexível, certas distinções tipológicas que já figuram em numerosos manuais e guias curriculares;

c) sejam relativamente homogêneos quanto às capacidades de linguagem dominantes implicadas na mestria dos gêneros agrupados. (SCHNEUWLY; DOLZ, 2004, p. 58-59)

O agrupamento estabelecido a partir desses critérios permite definir, para cada nível de ensino, quais serão os gêneros utilizados e que capacidades de uso da linguagem se procurará desenvolver mediante a didatização dos gêneros escolhidos. Os autores propõem a exploração didática nos diversos níveis do ensino fundamental de conjuntos de gêneros agrupados a partir de cinco características tipológicas: narrar, relatar, argumentar, expor e descrever ações.

No caso específico dos gêneros agrupados a partir da sua organização argumentativa (sua característica tipológica), esses gêneros são caracterizados, também, no domínio social de comunicação, pela discussão de problemas sociais 
controversos e por apresentar, como capacidades de linguagem dominantes, a sustentação, refutação e negociação de tomadas de posição.

Como conclusão do exemplo discutido neste capítulo, fica a certeza de que é hora de acertar o passo entre a inovação tecnológica associada à entrada do computador e da Internet nas escolas e as atividades de leitura e produção de textos em meio digital. O computador não é apenas uma máquina de escrever modernizada, mas um instrumento que possibilita formas diferenciadas de leitura e produção de textos. É um recurso que permite o acesso rápido a um volume de informações sem precedentes e privilegia a leitura centrada na intertextualidade. Entre os gêneros textuais que a escola pode selecionar para as atividades de produção de textos, a partir das sugestões de Schneuwly e Dolz (2004), é possível incluir alguns gêneros típicos do suporte digital, como os blogs, o hipertexto, o e-mail. Mesmo para a leitura e produção de outros gêneros, o computador pode ser um recurso importante, para reduzir a distância entre o que se aprende dentro e fora da escola.

\section{REFERÊNCIAS}

ADAM, Jean-Michel. Les textes: Types et prototypes. 4. ed. Paris: Nathan, 2001. 223 p.

BRASIL, Secretaria de Educação Fundamental. Parâmetros curriculares nacionais: terceiro e quarto ciclos do ensino fundamental: língua portuguesa. Brasília: MEC/ SEF, 1998. 87 p.

CAVALCANTE, Marianne Carvalho Bezerra. Mapeamento e produção de sentido: os links no hipertexto. In: MARCUSCHI, Luiz Antônio; XAVIER, Antônio Carlos (Orgs.). Hipertexto e gêneros digitais. Rio de Janeiro: Lucerna, 2005. p. 163-169.

DE CRISTO, Cláudio Guilherme Tuma. Progressão referencial em redações on-line. 116 p. Dissertação (Mestrado em Letras/ Estudos Linguísticos) - Universidade Federal do Paraná. Curitiba, 2005.

HALTÉ, Jean-François. Discours explicatif: état et perspectives de la recherché. Repères, n. 77, p. 95-109.

MILIAN, Marta. Textos expositivos: el resumen. In: CAMPS, A. (Org.). Secuencias didácticas para aprender a escribir. Barcelona: Graó, 2003. p. 161-178. 
PÉCORA, Alcir. Problemas de redação. São Paulo: Martins Fontes, 1983. 98 p.

SCHNEUWLY, Bernard et al. Gêneros orais e escritos na escola. Campinas: Mercado de Letras, 2004. 278 p.

Texto recebido em 19 de outubro de 2008.

Texto aprovado em 30 de junho de 2009. 